\title{
Risk-Benefit Profile of Novel Anti-diabetic Drugs: Current Perspectives
}

Matteo Parisotto, Emanuel Raschi, Elisabetta Poluzzi, Giulio Marchesini and Fabrizio De Ponti

Department of Medical and Surgical Sciences, University of Bologna, Bologna, Italy

"Corresponding author: Fabrizio De Ponti, Pharmacology Unit, Department of Medical and Surgical Sciences, Via Irnerio, 48

40126 Bologna BO, Italy, Tel: 390512091805; E-mail: fabrizio.deponti@unibo.it

Received date: July 14, 2016; Accepted date: July 27, 2016; Published date: August 05, 2016

Copyright: ( 2016 Parisotto M, et al. This is an open-access article distributed under the terms of the Creative Commons Attribution License, which permits unrestricted use, distribution, and reproduction in any medium, provided the original author and source are credited.

We are facing a paradigm shift in the era of antidiabetics, because agents marketed after 2008 (i.e., after the rosiglitazone saga) are not only required to reduce levels of $\mathrm{HbA1}$, but also to demonstrate beneficial or at least neutral effect with regard to cardiovascular (CV) outcomes (Figure 1). This is of paramount relevance, considering that the risk of developing $\mathrm{CV}$ disease is two-fold higher in patients with diabetes compared with individuals without diabetes [1]. Thus, pharmacovigilance is gaining a crucial role in guiding research and supporting clinical practice.

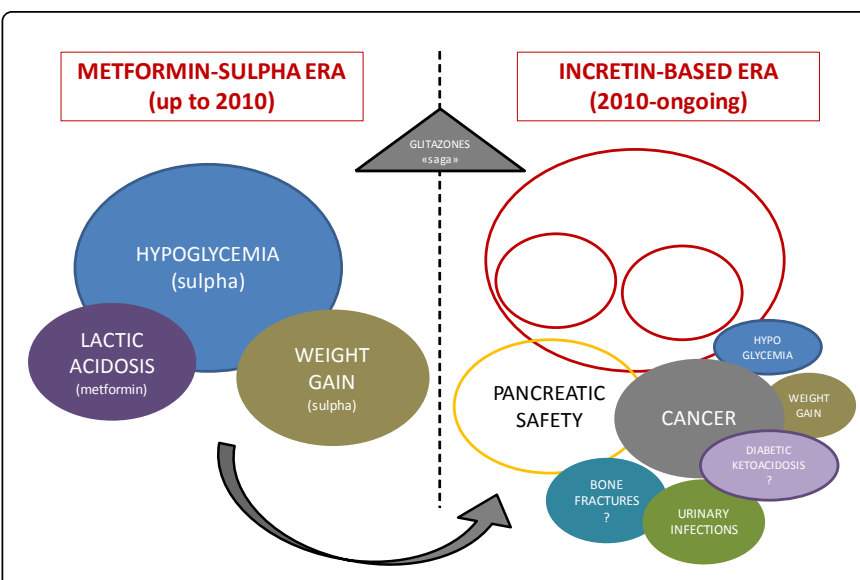

Figure 1: Evolving concepts in the perception (i.e., research priority and clinical implications) of safety issues related to antidiabetic drugs. HF: Heart Failure; MI: Myocardial Infarction.

Therefore, CV safety in patients with type 2 diabetes mellitus (T2DM) has recently gained an outstanding importance and dedicated clinical trials were designed, especially for most recent anti-diabetic classes. Among the published studies, TECOS, EXAMINE and SAVOR-TIMI addressed the CV safety of dypeptidyl peptidase 4 (DPP4) inhibitors (known as gliptins); ELIXA and LEADER analysed $\mathrm{CV}$ outcomes of lixisenatide and liraglutide (GLP-1 agonists), respectively; EMPA-REG-OUTCOME investigated the CV effect of empagliflozin, belonging to the latest pharmacological class of gliflozins, inhibiting the renal sodium-glucose transporter 2 (SGLT-2) (Table 1).

As regards incretin-based therapy, the risk-benefit profile is well established: incretin treatment carries a low risk of hypoglycaemia, but a mildly increased incidence of pancreatitis [2]. As to CV effects, a higher rate of hospitalization for heart failure (HF) emerged for some agents: SAVOR-TIMI reported an unexpected increase in the risk of $\mathrm{HF}$ in patients treated with saxagliptin compared to placebo; the increase in HF was higher in the first year of treatment and in patients with other risk factors for HF. In the EXAMINE trial, no statistically significant differences for the primary $\mathrm{CV}$ endpoint were demonstrated between alogliptin and placebo groups, although a trend for HF hospitalization was observed in patients with recent acute coronary syndrome [3]. Finally, TECOS documented no increased risk of $\mathrm{CV}$ outcomes and HF for sitagliptin, in keeping with possible drug specificity. This is an example of a pragmatic trial focused on CV outcomes in patients at risk of CV events in the setting of glycaemic equipoise, in order to limit biases related to different glycaemic levels [4].

Also data on gliflozins are accruing. The results of the EMPA-REGOUTCOME trial attracted a lot of interest because of the unanticipated large CV benefit: with the exception of UKPDS with metformin, in fact, all large trials aimed at better glucose control failed to show a remarkable improvement in CV outcomes. Patients treated with empagliflozin had significantly lower rate of the primary endpoint (MACE=composite of $\mathrm{CV}$ death, non-fatal myocardial infarction or stroke); CV death, non-fatal myocardial infarction or stroke occurred in $10.5 \%$ of the pooled treated group vs. $12.1 \%$ of the placebo group $[3,5]$. An unresolved issue regards the underlying mechanism implicated in reduced $\mathrm{CV}$ and total mortality, in the absence of significant decrease in myocardial infarction and death: beyond the documented reduction of blood pressure, it is likely that additional hemodynamic and/or metabolic effects are involved. Moreover, it is still unclear whether or not a class effect actually exists or, conversely, may be specifically attributed to the pharmacological properties of empagliflozin, showing higher selectivity on SGLT-2 cotransporter (IC50 for SGLT-2=3.1 vs. IC50 for SGLT-1=8,300) [6]. Results of similar studies conducted with dapagliflozin (DECLARE-TIMI58) and canagliflozin (CANVAS) will be available in 2019 and 2017, respectively, and will clarify this issue.

Within the CV issue, an additional unresolved aspect regards the generalizability of results to patients with lower $\mathrm{CV}$ risk and the persistence of the $\mathrm{CV}$ benefit (for empagliflozin) in the long-term, considering that all these studies have a limited duration (maximum 3 years); longer follow-ups are mandatory to evaluate all the aspects of progression of micro-vascular and macro-vascular damage related to glycaemic control. 
Citation: Parisotto M, Raschi E, Poluzzi E, Marchesini E, De Ponti F (2016) Risk-Benefit Profile of Novel Anti-diabetic Drugs: Current Perspectives. J Pharmacovigil 4: e160. doi:10.4172/2329-6887.1000e160

Page 2 of 3

\begin{tabular}{|c|c|c|c|c|c|c|}
\hline & SAVOR-TIMI 53 & EXAMINE & TECOS & ELIXA & LEADER & $\begin{array}{l}\text { EMPAREG- } \\
\text { OUTCOME }\end{array}$ \\
\hline Drug & Saxagliptin & Alogliptin & Sitagliptin & Lixisenatide & Liraglutide & Empagliflozin \\
\hline Design & Superiority & Non-inferiority & Non-inferiority & Non-inferiority & Non-inferiority & Non-inferiority \\
\hline n. patients & 16,492 & 5,380 & 14,671 & 6,068 & 9,340 & 7,028 \\
\hline Population & $\begin{array}{l}\text { T2DM with pre-existing } \\
\text { CVD or risk factors for } \\
\text { CVD }\end{array}$ & $\begin{array}{l}\text { T2DM with ACS within } \\
15-90 \text { days }\end{array}$ & $\begin{array}{l}\text { T2DM with pre- } \\
\text { existing } \\
\text { glycemic equipoise }\end{array}$ & $\begin{array}{l}\text { T2DM with ACS within } \\
180 \text { days, glycemic } \\
\text { equipoise }\end{array}$ & $\begin{array}{l}\text { T2DM aged } \geq 50 \text { with at } \\
\text { least one coexisting } \\
\text { CVD }\end{array}$ & $\begin{array}{l}\text { T2DM with } \\
\text { established CVD, } \\
\text { glycemic equipoise }\end{array}$ \\
\hline $\begin{array}{l}\text { Follow up } \\
\text { (median) }\end{array}$ & 2.1 years & 1.5 years & 3 years & 2.1 years & 3.8 years & 3.1 years \\
\hline $\begin{array}{l}\text { Baseline } \\
\text { HbA1c } \\
\text { (median) }\end{array}$ & 8 & 8 & 7.2 & 7.7 & 8.7 & 8.1 \\
\hline $\begin{array}{l}\text { Primary } \\
\text { endpoint }\end{array}$ & $\begin{array}{lr}\text { Composite of CV death, } \\
\text { MI, } & \text { stroke, } \\
\text { hospitalization } & \text { for } \\
\text { unstable } & \text { angina, } \\
\text { coronary } & \\
\text { revascularization or HF }\end{array}$ & $\begin{array}{l}\text { Composite of death } \\
\text { from CV causes, } \\
\text { nonfatal MI, or nonfatal } \\
\text { stroke }\end{array}$ & $\begin{array}{lr}\text { Composite of } & \mathrm{CV} \\
\text { death, nonfatal } & \mathrm{MI}, \\
\text { nonfatal stroke, or } \\
\text { hospitalization } & \text { for } \\
\text { unstable angina } & \end{array}$ & $\begin{array}{l}\text { Composite of the first } \\
\text { occurrence of death } \\
\text { from CV causes, } \\
\text { nonfatal MI, nonfatal }\end{array}$ & $\begin{array}{l}\text { First occurrence of } \\
\text { death from } \mathrm{CV} \text { causes, } \\
\text { nonfatal } \\
\text { silent) } \mathrm{MI} \text {, or nonfluding } \\
\text { stroke }\end{array}$ & $\begin{array}{l}\text { Composite of death } \\
\text { from CV causes, } \\
\text { nonfatal MI } \\
\text { (excluding silent MI), } \\
\text { or nonfatal stroke }\end{array}$ \\
\hline $\begin{array}{l}\text { Secondary } \\
\text { endpoints }\end{array}$ & $\begin{array}{l}\text { Hospitalization for } \mathrm{HF} \text {, } \\
\text { coronary } \\
\text { revascularization, or } \\
\text { unstable angina. }\end{array}$ & $\begin{array}{l}\text { Urgent } \\
\text { revascularization due } \\
\text { to unstable angina } \\
\text { within } 24 \text { h after } \\
\text { hospital admission }\end{array}$ & $\begin{array}{l}\text { First confirmed event } \\
\text { of CV death, } \\
\text { nonfatal MI, or } \\
\text { nonfatal stroke; } \\
\text { individual } \\
\text { components of the } \\
\text { primary composite } \\
\text { outcome, including } \\
\text { hospitalization for } \\
\text { HF. }\end{array}$ & $\begin{array}{l}\text { Composite of the } \\
\text { primary endpoint or } \\
\text { hospitalization for HF } \\
\text { and a composite of the } \\
\text { primary endpoint, } \\
\text { hospitalization for heart } \\
\text { failure, or coronary } \\
\text { revascularization } \\
\text { procedures }\end{array}$ & $\begin{array}{l}\text { Expanded composite } \\
\mathrm{CV} \text { outcome (plus } \\
\text { coronary } \\
\text { revascularization, or } \\
\text { hospitalization for } \\
\text { unstable angina pectoris } \\
\text { or HF), death from any } \\
\text { cause, a composite } \\
\text { renal and retinal } \\
\text { microvascular outcome, } \\
\text { neoplasms r and } \\
\text { pancreatitis }\end{array}$ & $\begin{array}{l}\text { Composite of the } \\
\text { primary outcome } \\
\text { plus hospitalization } \\
\text { for unstable angina }\end{array}$ \\
\hline \multirow{3}{*}{ Results } & $\begin{array}{l}\text { Superiority } \quad \text { NOT } \\
\text { ACHIEVED }\end{array}$ & $\begin{array}{l}\text { Non-inferiority } \\
\text { ACHIEVED }\end{array}$ & $\begin{array}{l}\text { Non- inferiority } \\
\text { ACHIEVED }\end{array}$ & $\begin{array}{l}\text { Non-inferiority } \\
\text { ACHIEVED }\end{array}$ & $\begin{array}{l}\text { Non-inferiority } \\
\text { ACHIEVED }\end{array}$ & $\begin{array}{l}\text { Non-inferiority } \\
\text { ACHIEVED }\end{array}$ \\
\hline & $\begin{array}{l}\text { Primary } \quad \text { endpoint: } \\
\mathrm{HR}=1.03(0.91-1.17)\end{array}$ & $\begin{array}{lr}\text { Primary } & \text { endpoint: } \\
\mathrm{HR}=0.96 & \text { (upper } \\
\text { boundary } & \text { of } \\
\text { sided } & \text { repeated } \\
\mathrm{Cl}=1.16) . & \end{array}$ & $\begin{array}{lr}\text { Primary } & \text { endpoint: } \\
H R=0.98 & (0.89- \\
1.08) & \end{array}$ & $\begin{array}{l}\text { Primary endpoint: } \\
\mathrm{HR}=1.02(0.89-1.17)\end{array}$ & $\begin{array}{l}\text { Primary endpoint: } \\
\mathrm{HR}=0.87(0.78-0.97)\end{array}$ & $\begin{array}{l}\text { Primary endpoint: } \\
\mathrm{HR}=0.86(0.74-0.99)\end{array}$ \\
\hline & $\begin{array}{l}\text { Hospitalization for HF: } \\
H R=1.27(1.07-1.51)\end{array}$ & $\begin{array}{l}\text { Hospitalization for HF: } \\
H R=1.19(0.89-1.89)\end{array}$ & $\begin{array}{l}\text { Hospitalization for } \\
\text { HF: HR=1.00 (0.83- } \\
1.20)\end{array}$ & $\begin{array}{l}\text { Hospitalization for HF: } \\
H R=0.96(0.75-1.23)\end{array}$ & $\begin{array}{l}\text { Hospitalization for HF: } \\
H R=0.87(0.73-1.05)\end{array}$ & $\begin{array}{l}\text { Death from CV } \\
\text { causes: HR=0.62 } \\
(0.49-0.77) \\
\text { Hospitalization for } \\
\text { HF: HR=0.65 }(0.50- \\
0.85)\end{array}$ \\
\hline
\end{tabular}

MI: Myocardial Infarction; HF: Heart Failure; CDV: Cardiovascular Disease; ACS: Acute Coronary Syndrome; T2DM: Type 2 Diabetes Mellitus; HR: Hazard Ratio (in parenthesis $95 \%$ confidence interval)

Table 1: Synopsis of published cardiovascular outcome trials.

From a safety standpoint, the harmful effects of gliflozins have been examined in many pre-approval trials. Predictable side effects are urinary tract infections (UTI) and genital infections (GTI), which are related to the mechanism of action of SGLT-2 inhibitors: increased and sustained glycosuria may facilitate the growth of microorganisms. UTIs occur in approximately $5 \%$ of gliflozin users, while GTIs occur in $5-10 \%$ of users, especially in females. All these adverse effects are generally mild or moderate and they all respond to standard antibiotics therapy; although few cases of pyelonephritis have been reported [6,7]. Hypovolemia is another possible predictable side effect related to the drug-related osmotic diuresis that may lead to volume depletion, reduced blood pressure and orthostatic hypotension; these conditions were more frequent in patients with predisposing factors such as elderly subjects, patients with moderate renal impairment or concomitant treatment with loop diuretics. Fasting hypoglycaemia rare and possibly unrelated to gliflozins; it has been reported in patients with a co-administration of sulfonylurea or insulin.

Ketoacidosis and impaired kidney functions are debated adverse effects. As of May 2015, the Food and Drug Administration (FDA) received 73 cases of ketoacidosis in patients treated with gliflozins (reported in the FDA Adverse Event Reporting System - FAERS database). The peculiarity of event is that nearly all cases were associated with normal blood glucose levels: for this reason it has been named "euglycaemic ketoacidosis". This condition is mostly associated with triggering factors such as infections, surgical procedure, trauma, reduced food and fluid intake. Besides, it could be associated with gliflozins related hyperglucagonemia which could be responsible for a 
higher hepatic ketone production, hypovolemia and frequent infections $[7,8]$.

The relationship between gliflozins and renal impairment is still uncertain: in clinical studies increased serum creatinine and reduction from baseline GFR were seen in $1-4 \%$ of gliflozin-treated patients. These changes were much larger in patients with previous moderate renal impairment (GFR $<60 \mathrm{~mL} / \mathrm{min}$ ), in older patients (age $>65)$ or in patients using diuretics. These effects were dose related and in most cases of mild/moderate intensity, with a return to previous baseline GFR after drug interruption. Acute reductions in GFR could be ascribed to hemodynamic effects (decrease in plasma volume and in blood pressure) or could be the consequence of tubule glomerular feedback due to increased delivery of sodium to the macula densa. This consequence might also be related to nephron glucotoxicity, linked to the mechanism of action of gliflozins [9]. The FDA also received 101 cases of acute kidney injury with sufficient detail to confirm the diagnosis and demonstrate a temporal relationship with canagliflozin (73 patients) and dapaglifozin (28 patients): these data could be the starting point for further analysis that will delineate the renal consequences of long-term exposure to SGLT-2 inhibitors. Considering that renal function could be progressively impaired by poor glucose control, drug-drug interactions and regular monitoring of renal function are mandatory.

The final consideration regards the place in therapy of these drugs and the optimal combination and sequence in diabetes management, considering that current guidelines strongly advocate for tailored therapy. As for pioglitazone, the potential cardiovascular benefit from the proactive study must be balanced against the documented increase of bladder cancer risk, a controversial and not fully understood adverse reaction also reported with gliflozins (especially dapagliflozin) [10] Accordingly, the current European summary of product characteristics does not recommend the association of SGLT-2 inhibitors with pioglitazone as a precautionary measure [11].

In conclusion, there is a key role for pharmacovigilance in the era of $\mathrm{CV}$ outcomes trials of novel anti-diabetic drugs: the present uncertainty on their overall risk/benefit profile, especially the newer pharmacological class of gliflozins, calls for data coming from post- authorisation safety studies (e.g., spontaneous reporting system and analytical observational studies) in order to guarantee the full characterisation of the $\mathrm{CV}$ effects as well as other rare safety issues. We also need to clarify the mechanism of action of gliflozins in renal tubules, as well as in all other organs where SGLT are expressed in order to better predict and understand side effects. This might help to define the optimal therapeutic strategy, once all pros and cons of antidiabetic drugs are clarified.

\section{References}

1. Coch RW, Green JB (2016) Current cardiovascular outcomes trials in type 2 diabetes: Perspectives and insight. Nutr Metab Cardiovasc Dis.

2. Palmer SC, Mavridis D, Nicolucci A, Johnson DW, Tonelli M, et al. (2016) Comparison of Clinical Outcomes and Adverse Events Associated With Glucose-Lowering Drugs in Patients With Type 2 Diabetes: A Metaanalysis. JAMA 316: 313-324.

3. Bonadonna RC, Borghi C, Consoli A, Volpe M (2016) Novel antidiabetic drugs and cardiovascular risk: Primum non nocere. Nutr Metab Cardiovasc Dis.

4. Green JB, Bethel MA, Armstrong PW, Buse JB, Engel SS, et al. (2015) Effect of Sitagliptin on Cardiovascular Outcomes in Type 2 Diabetes. N Engl J Med 373: 232-242.

5. Scheen AJ (2016) Reduction in cardiovascular and all-cause mortality in the EMPA-REG OUTCOME trial: A critical analysis. Diabetes Metab 42: 71-76.

6. Faillie JL (2016) Pharmacological aspects of the safety of gliflozins. Pharmacol Res.

7. Dailey G (2015) Empagliflozin for the treatment of type 2 diabetes mellitus: An overview of safety and efficacy based on Phase 3 trials. J Diabetes 7: 448-461.

8. Peters AL, Buschur EO, Buse JB, Cohan P, Diner JC, et al. (2015) Euglycemic Diabetic Ketoacidosis: A Potential Complication of Treatment With Sodium-Glucose Cotransporter 2 Inhibition. Diabetes Care 38: 1687-1693.

9. Hinnen D (2015) Glucuretic effects and renal safety of dapagliflozin in patients with type 2 diabetes. Ther Adv Endocrinol Metab 6: 92-102.

10. Lin HW, Tseng CH (2014) A Review on the Relationship between SGLT2 Inhibitors and Cancer. Int J Endocrinol 2014.

11. Forxiga (2014) European Medicines Agency. 